\title{
Prepatellar swelling in a football player
}

\author{
Noushin Yahyavi-Firouz-Abadi • Jennifer L. Demertzis
}

Received: 29 December 2011 / Revised: 2 March 2012 / Accepted: 6 March 2012 /Published online: 17 April 2012

(C) ISS 2012

\section{Question:}

A 16-year-old football player presents with a 4-week history of left prepatellar and infrapatellar pain and swelling following a direct blow to the knee, symptoms exacerbated by repetitive trauma during subsequent practices. Icing, compression wraps, and oral anti-inflammatory medication provided minimal relief. Left knee radiographs and MRI were performed (Figs. 1, 2, 3, and 4).

The diagnosis can be found at doi:10.1007/s00256-012-1398-1.

N. Yahyavi-Firouz-Abadi $(\bowtie)$

Mallinckrodt Institute of Radiology,

510 South Kingshighway Boulevard, Campus Box 8131,

St. Louis, MO 63110, USA

e-mail: yahyavin@mir.wustl.edu

\section{J. L. Demertzis}

Division of Musculoskeletal Radiology,

Mallinckrodt Institute of Radiology,

510 South Kingshighway Boulevard, Campus Box 8131,

St. Louis, MO 63110, USA

e-mail: demertzisj@mir.wustl.edu 


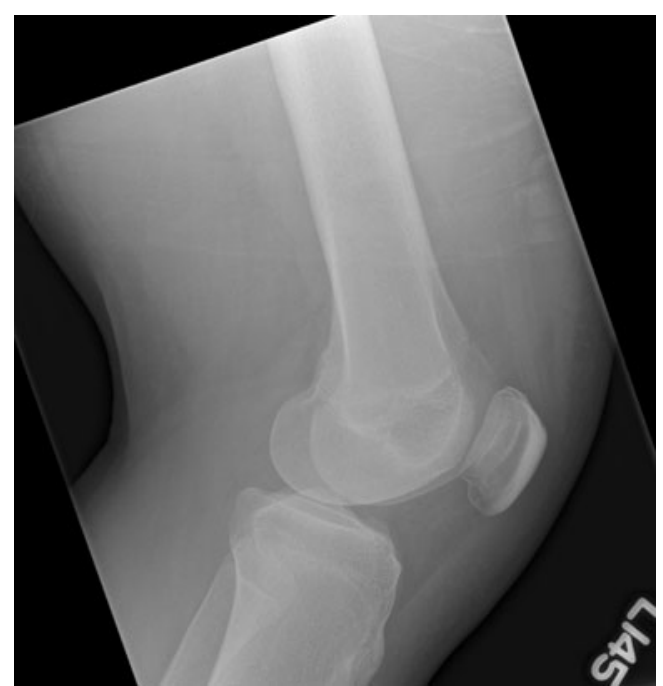

Fig. 1 Lateral radiograph of the left knee

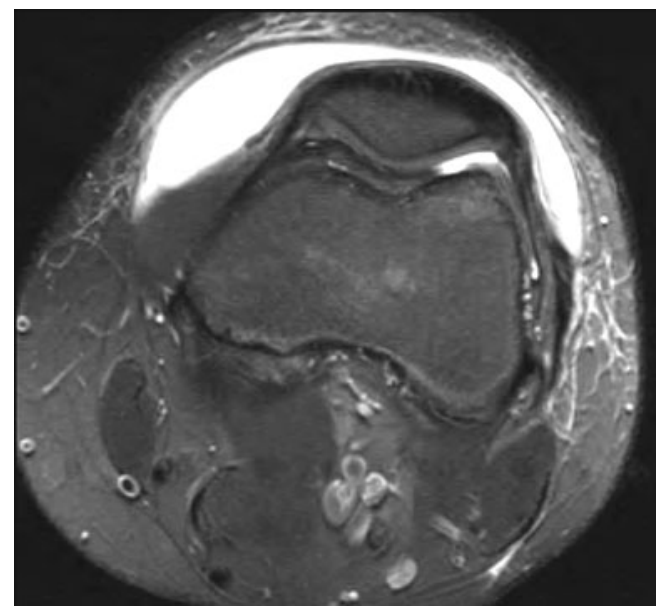

Fig. 2 Transverse fast spin-echo T2-weighted image at the level of the patella

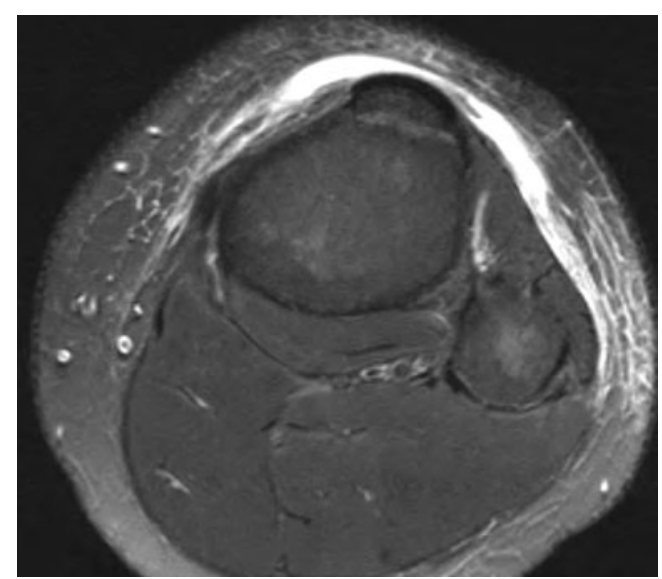

Fig. 3 Transverse fast spin-echo T2-weighted image at the level of the proximal tibia and fibula

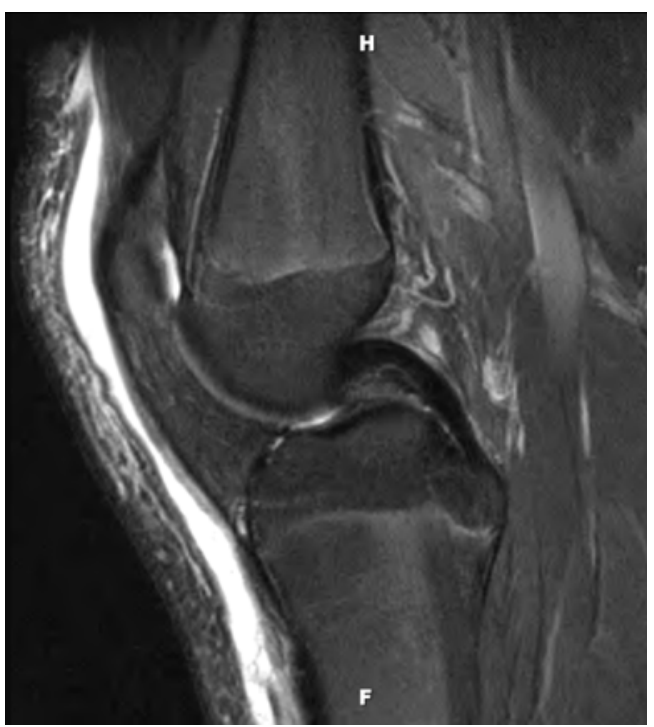

Fig. 4 Sagittal fast spin-echo T2-weighted image of the knee 